\title{
DURAÇÃO DO PERÍODO DE FORMAÇÃO DO GRÃO EM TRIGO
}

\author{
E.A. OSÓRIO'; W. WENDT ${ }^{2}$ \\ 'Depto de Fitotecnia-FAEM/UFPel - C.P. 354, CEP 96010-900 - Pelotas, RS. \\ ${ }^{2}$ CPAIT-EMBRAPA, C.P. 403, CEP: 96001 -970-Pelotas, RS.
}

\begin{abstract}
RESUMO: Admitindo a existência de correlaçăo positiva entre o tempo de enchimento dos gräos e a produtividade, foi estudada a duração do período de formação dos grāos em cultivares brasileiras de trigo. Os resultados obtidos demonstram existir grande variaçăo entre cultivares na duração deste periodo, o qual mostron-se menor nas cultivares tardias de ciclo vegetativo longo. Destacaram-se, por possuirem longo perfodo de formação dos grâos, as cultivares superprecoces SB 7519, CEP 7596 e IAS 58; as cultivares precoces Jacui, PF 75171, CNT 9, PEL 72393, Frontana, PAT 7392, IAS 54, Corilha, Cotiporă e Nobre e as cultivares de ciclo intermediário CNT 8 e PEL 72390. Nenhuma cultivar tardia dentre as testadas evidenciou longo perfodo do espigamento à colheita.

Descritores: trigo, Triticum aestivum, formaçāo do grāo, cultivar
\end{abstract}

\section{DURATION OF THE GRAIN FILLING PERIOD IN WHEAT}

\begin{abstract}
Assuming positive correlation between the grain filling period duration and yield this character was studied for 38 Brazilian wheat cultivars. Results demonstrate a great variation in the grain filling period duration that was shorter in late than in earlier cultlvars. The following earlier and semi-late cultivars had the longest grain filling period: SB 7519, CEP 7596, IAS 58, Jacui, PF 75171, CNT 9, PEL 72393, Frontana, PAT 7392, IAS 54, Coxilha, Cotiporā, Nobre CNT 8 and PEL 72390. None of the tested late cultivars has shown a long period from heading to harvest.

Key Words: wheat, Triticum aestivum, cultivar
\end{abstract}

\section{INTRODUÇÃO}

Os melhoristas necessitam, (LOOMS et al., 1979) informações adequadas sobre o tipo de planta a ser desenvolvido e sobre os processos básicos envolvidos.

Para SNYDER \& CARLSON (1984) a distribuição diferencial e o depósito de assimilados nos diferentes órgãos, tecidos e células devem ser feitos da forma mais eficiente possível, definindo eficiência como o acréscimo de produto por unidade de recurso utilizado (energia radiante absorvida, no caso).

Tendo os cereais poucos órgãos de reserva para nutrirem os grãos em formação, estreita associação tem sido feita entre o rendimento de grãos e a duração do periodo de atividade assimilatória da área fotossintetizante durante a fase de enchimento dos grãos.

A contribuição dos assimilados acumulados antes da antese para o enchimento dos grãos em cereais tem sido estimada em percentuais inferiores a $20 \%$. Tendo GALLAGHER et al. (1975) relatado contribuição da ordem de $43 \%$ em trigo e ceva$\mathrm{da}$, BDINGER et al. (1977), usando ${ }^{14} \mathrm{CO}_{2} \mathrm{em}$ in- tervalos periódicos antes e após a antese constataram que a contribuição dos assimilados acumulados antes da antese para o enchimento dos grãos de trigo situava-se em $12 \%$ (sob irrigação) e $22 \%$ (com deficiência hídrica), concluindo ter GALLAGHER et al. (1975), superestimado a importância da contribuição dos assimilados de pré-antese.

Para BOROJEVIC (1986) o prolongamento do ciclo vegetativo tende a aumentar a produção de biomassa total, enquanto o aumento do periodo de formação dos grãos traria como consequência promover acréscimos diretos no enchimento destes. $O$ autor acredita que o ciclo vegetativo longo não guarda relação direta com elevado rendimento de grãos conquanto longo periodo de formação dos grãos proporcionaria aumento da produtividade. Entende ainda ser conveniente alongar, em cereais, o tempo do florescimento à maturação, antecipando a floração sem encurtar o ciclo até a maturação.

A presente pesquisa pretendeu conhecer a duração do período de formação dos grãos das cultivares brasileiras de trigo no intuito de indicar, aos melhoristas, alguns genótipos de trigo com longo periodo de formação de grãos para uso em seus programas de criação de cultivares. 


\section{MATERIAL E METODOS}

Foram utilizados dados colhidos em quatro anos consecutivos, em Passo Fundo, RS (latitude $28^{\circ} 15^{\prime} \mathrm{S}$, longitude $52^{\circ} 24^{\prime} \mathrm{W}$ e altitude 684 metros) (WENDT, 1982).

Em cada ano foram semeadas 38 cultivares em 9 épocas distanciadas 15 dias entre si, de maio a setembro, constituida cada parcela por duas linhas de tres metros de comprimento espaçadas 0,20 metros. A adubação de base, seguindo Recomendação Oficial, foi de $250 \mathrm{~kg} / \mathrm{ha}$ da fórmula 8-26-20, com cobertura nitrogenada após 40-45 dias da emergência.

Afora outras observaçōes, em cada parcela foi anotado o início do espigamento (25\% das plantas com emissão total da espiga) e a data de maturação, identificada pela dureza do grão pressionado com a unha.
Para evitar a influência da temperatura e do fotoperiodo crescente, encurtando de forma diferenciada as fases de desenvolvimento de cultivares de ciclos diferentes, estas foram reunidas por data de espigamento, em 4 grupos, computando-se no primeiro os dados referentes aos espigamentos ocorridos entre 10 e 22/9; no segundo entre $23 / 9$ e $02 /$ 10 ; no terceiro entre 03 e $18 / 10$ e no quarto grupo referente aos espigamentos entre 19 e 29/10. As análises foram procedidas usando médias dos 4 anos de observaçăo.

Para estudar a duração das fases de desenvolvimento das plantas, as cultivares foram reunidas em 4 grupos Bioclimáticos de Maturação, determinados pelo Indice Hélio-térmico de Geslin, denominadas super-precoces, precoces, intermediárias e tardias (MOTA \& GOEDERT, 1969).

$O$ esquema experimental utilizado foi - de blocos ao acaso, considerando época de

TABELA 1.Número médio de dias até o espigamento das cultivares de trigo por grupo bioclimático de maturaçăo, conforme a época de espigamento.

\begin{tabular}{|c|c|c|c|c|c|}
\hline \multirow{2}{*}{$\begin{array}{l}\text { Grupo Bioclimático } \\
\text { de Maturaçãao }\end{array}$} & \multicolumn{4}{|c|}{ N MÉDIO DE DIAS ATÉ O ESPIGAMENTO } & \multirow[b]{2}{*}{ Média } \\
\hline & $\begin{array}{c}\text { Espigamento entre } \\
10 \mathrm{e} 22 / 9\end{array}$ & $\begin{array}{l}\text { Espigamento entre } \\
23 / 9 \text { e } 02 / 10\end{array}$ & $\begin{array}{c}\text { Espigamento entre } \\
03 \text { e } 18 / 10\end{array}$ & $\begin{array}{c}\text { Espigamento entre } \\
19 \text { e } 29 / 10\end{array}$ & \\
\hline Super-precoce & 77,7 & 72,0 & 68,0 & 62,4 & $70,0 \mathrm{a}$ \\
\hline Precoce & 87,3 & 83,0 & 76,6 & 73,9 & 80,2 b \\
\hline Intermediário & 97,2 & 93,0 & 85,6 & 79,0 & $88,7 \mathrm{c}$ \\
\hline Tardio & 122,0 & 120,2 & 116,2 & 97,4 & $113,9 d$ \\
\hline MÉDIA & $91,1 \mathrm{~A}$ & 86,9 B & $81,2 \mathrm{C}$ & 75,2 D & 3,6 \\
\hline
\end{tabular}

Médias acompanhadas por letras iguais não diferem significativamente a nivel de $5 \%$ de probabilidade. Coeficiente de variação $=8,4 \%$

TABELA 2. Número médio de dias do espigamento à maturação das cultivares de trigo por grupo bioclimático de maturação, conforme a época de espigamento.

No MÉDIO DE DIAS ATÉ O ESPIGAMENTO

Grupo Bioclimático

\begin{tabular}{lccccc} 
de Maturação & $\begin{array}{c}\text { Espigamento entre } \\
10 \text { e } 22 / 9\end{array}$ & $\begin{array}{c}\text { Espigamento entre } \\
23 / 9 \text { e } 02 / 10\end{array}$ & $\begin{array}{c}\text { Espigamento entre } \\
03 \text { e } 18 / 10\end{array}$ & $\begin{array}{c}\text { Espigamento entre } \\
19 \text { e 29/10 }\end{array}$ & Média \\
\hline Super-precoce & 49,5 & 48,2 & 45,5 & 40,6 & 46,0 a \\
Precoce & 50,7 & 46,8 & 42,7 & 40,4 & 45,2 a \\
Intermediário & 50,8 & 46,8 & 42,0 & 41,8 & 45,4 a \\
Tardio & 45,8 & 45,2 & 41,6 & 34,4 & 41,7 b \\
\hline MÉDIA & $49,8 \mathrm{~A}$ & $46,9 \mathrm{~B}$ & $43,1 \mathrm{C}$ & $39,8 \mathrm{D}$ & 4,9 \\
\hline \hline
\end{tabular}

Médias acompanhadas por letras iguais não diferem significativamente a nível de $5 \%$ de probabilidade. Coeficiente de variação $=3,4 \%$. 


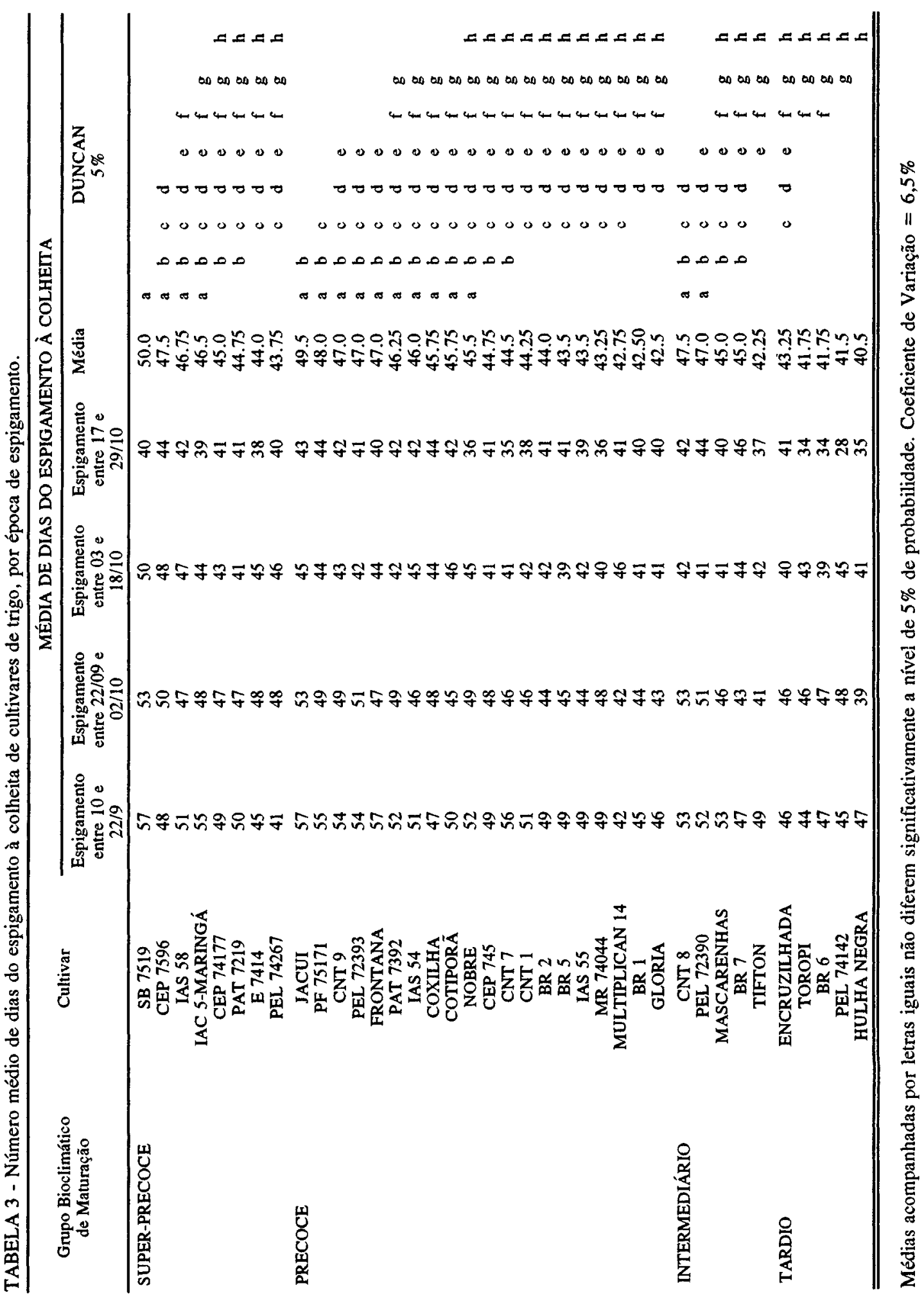


espigamento como bloco e cultivar como repetição, sendo as comparaçб̃es entre médias procedidas pelo teste de Duncan a nível de $5 \%$ de probabilidade.

\section{RESULTADOS E DISCUSSÃO}

A análise da duração da fase vegetativa (número de dias até o espigamento), por grupo bioclimático, mostrou (TABELA 1) diferença significativa entre as médias dos grupos, confirmando a espectativa visto ser este um dado influente na prévia caracterização dos grupos. Analisando a duração da fase vegetativa em função da época em que ocorreu o espigamento constatou-se significativa redução do ciclo com o atrazo do espigamento tendo o ciclo diminuido, em média, 1 dia para cada 2 dias de atraso no espigamento.

Quanto a duração da fase reprodutiva (período de formação dos grãos) apenas as cultivares tardias diferiram significativamente das demais, sendo 4 dias mais curto, em média (TABELA 2). Esta constatação pode estar explicando o fato das cultivares tardias, no que se refere ao ciclo mais longo, não promoverem nos sucessivos anos em que tem sido submetidas a ensaios de rendimento nesta localidade (Passo Fundo), produtividade maior do que as cultivares precoces.

Tal como constatado com o ciclo vegetativo, o período de formação dos grãos encurtou com o atrazo na época de espigamento, ocorrendo em média redução de 1 dia na fase reprodutiva para cada 3,7 dias de atrazo no espigamento.

Residindo o maior interesse da pesquisa na duração do período de enchimento dos grãos foi procedida, para este caráter, a análise dos dados por cultivar, comparadas as médias pelo teste de Duncan à $5 \%$ de probabilidade.

Foram encontradas, para número de dias de formação dos grãos, diferenças entre cultivares que superaram, na média, a 9 dias. Diferenças desta ordem ganham importância se considerado que a duração média da fase reprodutiva foi de 45 dias, representando portanto uma variação percentual superior a $20 \%$.

Os resultados da análise estatística da duração média do periodo de enchimento dos grãos por cultivar (TABELA 3) destacou, por possuirem um longo periodo de formação dos grăos, as cultivares super-precoces SB 7519, CEP 7596 e IAS 58; as cultivares precoces Jacui, PF 7571, CNT 9, Pel 72393, Fontana, PAT 7392, IAS 54, Coxilha, Cotiporã e Nobre; e as cultivares de ciclo intermediário CNT 8 e Pel 72390. Nenhuma cultivar tardia testada evidenciou longo período do espigamento à colheita.

\section{CONCLUSÃo}

Existe significativa variação, nas cultivares brasileiras de trigo, quanto a duração do periodo de formação dos grãos (ciclo reprodutivo) o qual se mostrou mais reduzido nas cultivares tardias, de ciclo vegetativo longo. A variação entre cultivares na duração média do ciclo reprodutivo superou a 9 dias, destacando-se por possuirem um longo período de formação dos grãos as cultivares super-precoces SB 7519, CEP 7596 e IAS 58; as cultivares precoces Jacui, PF 7571, CNT 9, Pel 72393, Fontana, PAT 7392, IAS 54, Corilha, Cotiporã e Nobre; e as cultivares de ciclo intermediário CNT 8 e Pel 72390. Nenhuma cultivar tardia dentre as testadas evidenciou longo período do espigamento à colheita.

\section{REFERÊNCIAS BIBLIOGRÁFICAS}

BIDINGER, F; MUSGRAVE, R.B.; FISCHER, R.A. Contribution of stored pre-anthesis assimilate to grain yield in wheat and barley. Nature, London, v.270, p.431-433, 1977.

BOROJEVIC, S. Breeding for yield in cereals. Novi Sadi: University of Novi Sad. Faculty of Agriculture, 1986. 125p.

GALLAGHER, J.N.; BISCOE, P.V.; SCOTT, R.K. Barley and its environment. V Stability of grain weight. Journal of Applied Ecology, Oxford, v.12, p.319-336, 1975.

LOOMIS, R.S.; RABBINGE, R.; Ng, E. Annual Review of Plant Physiology, Palo Alto, v.30, p.339-367, 1979

MOTA, F.S.; GOEDERT, C.O. Caracteristicas bioclimáticas de trigos sul brasileiros. Pesquisa Agropecułria Brasileira, Brasília, v.4, p.78-87, 1969.

SNYDER, F.W; CARLSON, G.E. Selecting for partitioning of photosynthetic products in crops. Advances in Agronomy, New York, v.37, p.47-72, 1984.

WENDT, W. Resposta de genótipos de trigo ao foto período e temperatura média sob condiçðes naturais. In: REUNIÃO NACIONAL DE PESQUISA DE TRIGO, 12., 1982. Cascavel. Resultados de pesquisa... Passo Fundo: EMBRAPA/CNPT, 1982. p.267-288.

Recebido para publicação em 09.08 .94

Aceito para publicação em 10.02.95 